\title{
Failures of Intention and Failed-Art
}

\author{
Michel-Antoine Xhignesse \\ Capilano University \\ michelxhignesse@,capilanou.ca
}

This is a penultimate draft. Please cite the final version: "Failures of Intention and FailedArt," Canadian Journal of Philosophy (forthcoming).

\begin{abstract}
This paper explores what happens when artists fail to execute their goals. I argue that taxonomies of failure in general, and of failed-art in particular, should focus on the attempts which generate the failed-entity, and that to do this they must be sensitive to an attempt's orientation. This account of failed-attempts delivers three important new insights into artistic practice: (1) there can be no accidental art, only deliberate and incidental art; (2) art's intention-dependence entails the possibility of performative failure, but not of failed-art; and (3) art's intention-dependence is perfectly compatible with the role that luck plays in artistic creation.
\end{abstract}

Keywords: accidental art; art-attempts; complex plans; failed-art; incidental art; intention; planning 


\section{Failures of Intention and Failed-Art}

\section{I - Introduction}

Most philosophical discussions of art today take for granted the premise that art-making is necessarily intentional. Artworks, after all, are artifacts, and artifacts are made by agents executing some sort of plan. The result is that art-making is an intention-dependent activity: it necessarily requires intentional action on an agent's part; natural objects, by contrast, are thoroughly intention-independent. And if the last sixty years of philosophical aesthetics is to be believed, then an entity's art-status depends on either (1) some feature of the process which generated it (proceduralism), or (2) the uses to which it is put by society (functionalism).

Most proceduralists have taken a positive approach to art's ontology, postulating necessary and sufficient conditions for art. These efforts have borne much fruit, but they have stalled in the face of accumulated anomalies. Instead, proceduralists should shift the focus of their attention away from artworks and their properties to the attempts from which they issue. It is the art-attempt, after all, that supposedly does all of the ontological heavy lifting, rather than the object itself. And in order to shift our focus, it is useful to adopt a negative approach and consider what happens when the relevant process breaks down.

Christy Mag Uidhir (2010, 2013) began this work by sketching a framework of failure in general, and an account of failed-art in particular. Failures, he argued, must satisfy three conditions:

(1) Attempt Condition: An object $w$ is the product of an F-attempt,

(2) Non-Art Condition: $w$ is not $F$ in the manner intended, and

(3) Failed-Art Condition: $w$ is not $F$ in the manner intended as the result of the $F$ attempt in (1). ${ }^{1}$

\footnotetext{
1 Mag Uidhir (2010: 394) and (2013: 19-20). Mag Uidhir phrases (2) and (3) such that $w$ does not possess $F$ in the manner intended. I have amended this to 'is not' to smooth the substitution of 'art' for ' $F$ '.
} 
The result of a failed F-attempt could thus be described as a failed-F; it is a simple enough matter, then, to generate a theory of failed-art by substituting 'art' for ' $P$ ' in the schema. ${ }^{2}$ Mag Uidhir further distinguishes between two types of failed-art, simple and complex failures. Simple failures occur when the product $w$ of an F-attempt is non-art (non-F) simpliciter, so, for example, when the result of my attempt to chisel a bust is a heap of rubble rather than any kind of statue. Complex failures occur when the object $w$ is "art" (F; or, at least, accords with its creator's plan), but not "in the manner intended," not as a result of the proper following of its creator's plan (and, thus, is not art after all).

This is a good start, but I shall argue that it falls short in a few important respects. First, I show in \II that it conflates the conformative and performative senses of 'failure'. Armed with this distinction I argue, in $§ I I I$, that an attempt's orientation constrains the types of failure which are salient to it. The upshot is that although the possibility of failure is a necessary corollary of intention-dependent activities such as art-making, the possibility of failed-art is not. Furthermore, I argue that this shows there can be no accidental art, only deliberate or incidental art. These concerns for the framework of failure's extensional adequacy, together with additional concerns about its descriptive adequacy, lead me, in $§ I V$, to construct a new taxonomy of failures. That taxonomy will allow me, in $\int \mathrm{V}$, to give a substantive explanation of just what is meant when we appeal to 'the manner intended'. Ultimately, I suggest that the problem stems from focusing on failure as a property of individual artifacts rather than of their underlying attempts. Finally, in SVI I offer an attempt-theory of failure which respects

\footnotetext{
2 The category of failed-art is informative because failed-artworks derive their non-art status from the particular way in which the art-attempt that generated them failed, whereas ordinary non-artworks, such as cats, trees, and sunsets, are not the result of any attempt whatsoever. In other words, their status as failures is intimately tied to their intention-dependence.

3 This formulation is a little misleading. It results from substituting 'art' for ' $F$ in Mag Uidhir's schema. The entity in question satisfies the success-conditions for an attempt to make an $F$, but it is actually non- $F$ because it is not $F$ in the manner intended, i.e., as a result of the maker's successful execution of her plan of action. We should thus say that the entity in question seems to be $F$, but is not.
} 
these insights, and which holds out the promise of a more satisfying explanation of failure, and just what it means for art-attempts in particular.

\section{II - Two senses of 'failure'}

Following a long tradition in action theory, I assume that an attempt is just an action guided by the intention that a particular goal obtain in the manner prescribed. Attempts thus consist of a goal and an intentional action (acting with the intention that $F$ ); attempts are successful when the goal obtains in the manner prescribed, and unsuccessful when the goal either does not obtain, or does not obtain in the manner prescribed. We can distinguish between two distinct orientations which attempts can have: the direct and the indirect. A direct attempt takes place when an agent intends to $\Phi$; an indirect attempt, by contrast, takes place when an agent (directly) intends to $\Psi$, where $\Psi$-ing entails the satisfaction of the conditions for $\Phi$. A successful indirect attempt to make art would thus yield what Dominic McIver Lopes has called 'incidental art'; by contrast, when the conditions are satisfied accidentally (i.e. the attempt fails but the result seems to satisfy the initial goal), we would have 'accidental art'. ${ }^{4}$

An art-attempt, then, is just any attempt whatsoever (direct or indirect), the satisfaction of whose success-conditions entails the satisfaction of the conditions for being art. Some of these attempts will be deliberate (as when Artemisia Gentileschi set out to paint Judith with the head of Holofernes), and some will be incidental (e.g. when prehistoric peoples painted cave walls, despite presumably having no concept of fine or "high" art). Notice that what counts as an art-attempt is determined by what it is for something to be art. Thus, for an institutionalist, location in and acceptance by an artworld public would be required; for an intentional-historical account it would be the intention that it fit into some

\footnotetext{
${ }^{4}$ Lopes (2007: 8).
} 
historical way of regarding art, and so on for other theories of art. The possibility of failure is dependent upon the success conditions of the enterprise in question, whatever these conditions might be; it is the epistemological role of a theory of art to supply just these success conditions.

There is, of course, a trivial sense in which art-attempts can fail: when, for example, an artist's creative activity is permanently disrupted. Should Agatha Christie's Amyas Crale formulate the intention to paint a portrait of his mistress but die before he can put brush to pigment then it is uncontroversial that he has failed to create an artwork. Should he die midprocess, we might have either an unfinished work that still counts as an artwork (like Coleridge's Kubla Khan), or no artwork at all (arguably, Duchamp's Woolworth Building is just such a case).

While some unfinished works are nonetheless artworks in their own right, the question of interrupted activity invokes the problem of vagueness. These are artworks-inprogress which were never completed; how far along does the artist have to get before we are willing to say that an art-attempt has taken place, and how much more is required before we are willing to class it as a successful attempt resulting in an artwork? One possibility is that a mere intention suffices, but this seems too inclusive and disconnected from any actual actions on the agent's part. ${ }^{5}$ If, for instance, Crale intends to paint a picture but never gets around to putting brush to canvas, then we do not have an art-attempt in the first place; the intention that a goal obtain in a particular manner is present, but the action is missing. The product (such as it is) will certainly be non-art, but it cannot be failed-art. A better option is to count as art-attempts only those artistic plans which the agent is directly in the process of

\footnotetext{
${ }^{5}$ Gideon Yaffe (2010) offers a detailed defense of this model of attempt liability. Yaffe's defense centres on the sphere of criminal law, however, and is motivated by the view that punishment justifiably targets criminal intentions. Artworld cases do not share this kind of theoretical backdrop, leaving the case for the sufficiency of intention that much weaker.
} 
executing. ${ }^{6}$ So, for example, going out to buy some paints and canvas would not constitute an art-attempt, but putting pigment to canvas would.

With that in mind, it should come as no surprise that one might fail to execute one's intention in different ways. One such, which I shall call the performative sense of failure, results from not fully or properly performing the requisite action. A second, conformative sense, results from not actually bringing about the desired consequences. ${ }^{7}$ Suppose, for instance, that Poirot asks his audience whether they have any questions about the murder he has just solved, and that Hastings intends to ask a question. Suppose further that, in order to do so, Hastings must first raise his hand to signal that he would like to ask a question. If for some reason Hastings does not successfully raise his hand, then his plan fails performatively because he does not actually perform the action required to fulfill his intention (to ask a question). If he does raise his hand (performative success) but Poirot misreads, ignores, or simply does not see his signal, then Hastings has failed conformatively because he has not brought about the desired result. Performative failures result from uncompleted or wrongheaded actions, while conformative failures result from completed actions that do not bring about the desired consequences.

The extent to which some particular course of action is a success or failure thus depends on the answers to two questions: (1) did the agent do what she set out to do in order to bring about the intended results, and (2) did the agent's actions actually bring about the intended result? We often succeed in the former while failing in the latter, as in Hastings's case. But what if someone were to achieve the desired outcome without successfully performing the action intended? Suppose that Miss Lemon, somewhat

\footnotetext{
${ }^{6}$ For a defense of this kind of attempt liability (in the context of criminal law), see Sarah Paul's excellent (2014).

${ }^{7}$ David Davies introduces these notions, under the guise of success and failure in-action/in-agency, in his (2018). I have introduced the conformative/performative terminology in order to avoid confusion (since both types of failure attach to actions).
} 
uncharacteristically, intends to scare Poirot with a fake can of peanut brittle. Miss Lemon brings it to her office with the intention of giving it to Poirot, but fails to do so for one reason or another. Now suppose that, hunting for a snack, Poirot comes across the can in Miss Lemon's office much later and opens it up only to make the terrifying discovery that it contains a spring-loaded cloth snake. While the results seem to conform to Miss Lemon's intentions, the series of events leading up to them does not reflect a successful course of action that she undertook (her earlier attempt to scare Poirot having been aborted). Since the result does not issue from an action on her part, Miss Lemon is not fully responsible for it: Poirot's scare is merely accidental. ${ }^{8}$ What this case serves to illustrate is that performative success is a precondition for conformative success. Exactly how a particular attempt fails, however, depends upon the success conditions of the attempt in question.

\section{III - Orienting attempts}

By distinguishing between failures of conformity and of performance, we are now equipped to see that direct and indirect attempts yield different types of failure. Direct attempts can fail either conformatively or performatively, while indirect attempts can only fail performatively.

Suppose, for example, that Hastings attempts the following:

Counting

Count (out loud) from 1 to 5 , inclusively.

Hastings's attempt here is direct: he explicitly takes Counting as his goal. In order to succeed, Hastings must (1) begin counting, and (2) offer the sequence (1, 2, 3, 4, 5). If Hastings does not first begin counting (e.g. he intends to do so, but never gets around to it), then he has not acted in the first place and, therefore, cannot be said to have failed (or succeeded). Once

\footnotetext{
8 As Nagel (1979) and Williams (1981) might put it, it is a matter of moral luck.
} 
Hastings actually begins to perform the requisite action under the appropriate orientation, we have a proper Counting-attempt. And that means (given the distinctions introduced in $\ \mathrm{II}$ ) that his attempt can fail in either of two sorts of ways:

(A) Because his attempt is aborted (i.e., it is abandoned or interrupted partway through) or goes awry, or

(B) Because the sequence offered does not conform to the goal governing the performance in (1).

If Hastings falls into trap (A) because he loses interest in Counting, then we have a trivial case of a failed Counting-attempt: Hastings attempted to satisfy Counting, did not produce a sequence satisfying Counting, and produced no result because he never actually completed the actions required to satisfy Counting. The failure here is purely performative. Likewise, if Hastings falls into trap (B) and sincerely offers the sequences $(1,2,4,3,5),(1,2,4,5)$, or (1, 2, 5), he will have failed in his Counting-attempt. The failure in this second case is conformative, meaning that Hastings will have successfully satisfied the attempt condition and generated a sequence of numbers, but that sequence does not satisfy his goal (it is $\neg F$ ). What is more, the product of his actions is $\neg F$ precisely because of the deviant way in which he went about trying to execute his goal (Counting). We thus have an instance of failedCounting.

So much for the direct cases; now, what about those which are indirect? Suppose that rather than Counting, Hastings instead attempts

Stating

State all and only the natural numbers between 1 and 5, inclusively and in ascending order.

Once again, Hastings's attempt is direct, since he is explicitly taking Stating as his goal. Its failure and success conditions will thus mirror those outlined for Counting above. What is special about Stating, however, is that it is satisfied by the same sequence of numbers as Counting, and vice-versa. The two differ intensionally, but the successful execution of the one entails the satisfaction of the success-conditions for the other, so we can describe direct 
attempts at the one as indirect attempts at the other. In the same way, a direct attempt to raise one's arm is an indirect attempt to send action potentials from the brain, through the nervous system, and to the motor neurons that innervate the relevant muscle fibres, resulting in the relevant muscle contractions, and this regardless of whether one knows anything about human anatomy.

The direct attempt constituting the indirect attempt can, as we saw above, fail in either of two ways (performatively or conformatively). But what about the co-extensive indirect attempt in each case? To the extent that Hastings counts by Stating his success or failure is incidental, since he does not attempt Counting directly. If Hastings fails to satisfy Stating then the product of his action (call it $P$ ) is bound to be a non-Counting, too, given that Counting and Stating have the same success conditions. To determine whether $P$ is also a failedCounting, however, we must determine whether the fact that it is a non-Counting is dependent upon Hastings's actual attempt.

This is clearly so when Hastings's attempt is aborted or goes awry: the reason $P$ is a non-Stating (and, thus, a non-Counting) is because Hastings's attempt was somehow inadequate. We thus have a performative failure to both State and Count. But now suppose that Hastings 'fails' because he offers the sequence $(1,2,4,3,5)$. Clearly, this is a conformatively failed-Stating. It is not, however, a conformatively failed-Counting because Counting was never the goal of Hastings's attempt. A successful Counting would have coincided with Hastings's goal, but it would not itself have been his goal. He might not even be aware that Counting is possible, after all! There is simply nothing connecting this description of the consequences of Hastings's actions to his intentions. The same will be true of any number of other equivalent descriptions of Hastings's action-e.g., Listing ("list the numbers..."), 
Mentioning ("mention the numbers..."), Setting ("make an ordered set of the numbers..."), etc. So, while indirect attempts might fail performatively, they do not fail conformatively.

We can now discern two broad consequences for artworks. First, a direct attempt can fail either conformatively or performatively, while an indirect attempt can only fail performatively. This means that, pace Mag Uidhir and the standard interpretation, only the failure of a direct art-attempt can result in failed-art, the failure of indirect art-attempts just results in non-art. This is so because to say that something is a failed- $x$ is to say (1) that a direct $x$-attempt was undertaken, and (2) that it was unsuccessful. The possibility of failed-art is therefore not a necessary consequence of art's intention-dependence; only the possibility of performative failure is. And that, in turn, shows that intention-dependence imposes a relatively weak constraint on successful art-making, one which can be satisfied indirectly as well as directly.

But secondly, if we assume that art-making is necessarily intention-dependent (as philosophers of art nigh-universally concede), then it also means that there can be no such thing as accidental art, only deliberate or (at worst) incidental art. ${ }^{9}$ This is because the accidental end-product is not the result of any successful attempt whatsoever, let alone a successful art-attempt, and thus it is not intention-dependent. Imagine, for instance, that I intend to make and put up a tent, but fail so spectacularly that I end up with an abstract sculpture instead (the kind of thing which an insufferable pedant might title Tent). ${ }^{10} \mathrm{I}$ certainly have an artifact on my hands, but that artifact is not the result of any successful intentional action on my part, and so it is not substantively intention-dependent, however it may look. It is a byproduct of failure, the result of a failed attempt. Its existence in the form it has is a matter of chance, and thus not substantively tied to my intentional action.

\footnotetext{
${ }^{9}$ c.f. Lopes (2007: esp. 8-9).

10 Although in this case, nobody titles it because nobody is trying to make an artwork.
} 


\section{IV - Taxonomies of failure}

The existing taxonomy of failure has the virtue of simplicity: failures are either complex or simple. But if the preceding remarks are correct, then this taxonomy is extensionally and descriptively inadequate. It is extensionally inadequate because not all failures are complex or simple; it is descriptively inadequate because it overstates the role that "the manner intended" plays in complex plans. Let us begin with its extensional inadequacy.

Recall that, according to the standard taxonomy, 'simple' failures occur when the product $w$ of an $F$-attempt is non- $F .{ }^{11}$ Simple failures are thus what I call "conformative" failures: the agent performs the requisite actions but the product of her attempt is non-art for whatever reason-that is to say, the product does not satisfy certain conditions external to the agent's activity which are necessary for its (intended) art-status. If the institutional theory of art is correct, for example, then this might be because the end result is deficient in some way that permanently precludes it from artworld uptake. Hastings might be so deceived about his artistic prowess that the end result of his efforts is wholly opaque and unintelligible to posterity.

'Complex' failures, on the other hand, are supposed to occur when the object $w$ appears to satisfy F, but does not do so "in the manner intended." This last fact is then taken to undermine its F-status in the first place. On the model I have suggested, complex failures should be classed as performative failures: the agent fails to successfully pull off the intended course of action, and this fact scuppers her artistic plans - the result is just non-art, though it might look like art. Because performative success is a precondition for conformative success, any pretence the product might have towards art-status is undermined by the failure of the attempt that preceded its production. Imagine, for instance, that Hastings intends to ask a

${ }^{11}$ Mag Uidhir (2013: 19-20). 
question during one of Poirot's little gatherings of suspects, and that he tells Poirot as much. Suppose he plans to raise his hand during the dénouement so that Poirot can call upon him to ask his question - but, when the time comes, Hastings feels intimidated and lowers his hand before Poirot can see it. But because Poirot remembers Hastings's plan, he nevertheless calls upon his old friend to ask his question. This looks like a case of complex failure-or of conformative success despite performative failure-since Hastings gets to ask his question despite failing to signal Poirot at the appropriate time. So it might be objected that although conformative success often or even usually requires performative success, it does not always do so. ${ }^{12}$

In a case like this one, everything hinges on how we understand Hastings's original plan. If Hastings's plan involved a normative commitment to doing things a certain waye.g. to ask a question by raising his hand during the dénouement-then we have a performative failure, which entails conformative failure, too. Hastings is lucky that he got to ask his question, because his opportunity to do so did not arise from the successful execution of his plan (rather, it was fulfilled by his friend's actions). If his plan was just to ask a question, broadly formulated and with no normative commitment to a more specific course of action, ${ }^{13}$ then we can say that Hastings was both conformatively and performatively successful, since he got to ask his question because he caused Poirot to take his desire into account by telling it to him. If Hastings had not told Poirot about his desire to ask a question, however, then Poirot's asking him whether he had a question would have been entirely coincidental. And so, while it might have looked like a conformative success (without performative success), it could not have been, since Hastings's asking a question would not have been the result of

12 I am obliged to the editor for making this suggestion.

13 This is what H.L.A. Hart described as a 'bare' intention or plan in his (1968: 117). 
any intentional action on his part. There would have been no relevant attempt in the first place.

Notice, however, that the failure of performance already secures the product's status as a failed- $x$; the issue of its uptake as $x$ does nothing to specify the mechanism of failure. Thus, whereas "simple" failures pick out the entire class of conformative failures, "complex" failures merely name the subclass of performative failures whose products seem to be artworks (or whatever else) but in fact are not. Another relevant subclass of performative failures would be those that do not enjoy uptake as art, for example - that is to say, those which are not art (because the requisite actions were not performed, or not performed properly) and which do not fool anyone into thinking that they might be. Let us call these 'uncomplicated' failures to distinguish them from their complex counterparts.

Closer inspection reveals that complex failures are just the accidental by-blow of a failed direct attempt. While it is easy enough to imagine such cases in principle, it is a different matter entirely to identify them in practice. Uncomplicated failures, on the other hand, are intuitively much more populous since they do not require proper uptake. Their identification is likewise much more easily accomplished. In the artworld, for example, these might include Duchamp's Woolworth Building, the plan for which he formulated but never actually executed. The first problem with the standard taxonomy, then, is that it is hardly exhaustive; 'simple' failures pick out the whole class of conformative failures, but 'complex' failures only pick out a single kind of performative failure, leaving uncomplicated failures entirely unanalyzed.

The second - and, I think, more serious-problem with the standard taxonomy of failure concerns its reliance on "the manner intended." Any account that places such a hefty premium on so vague a notion owes us some explanation of its content. One plausible 
explanation is that "the manner intended" amounts to a requirement that the attempt be directly intended. This move is analogous to that which was supposed to relieve the causal theory of action from the problem of wayward causation, and it is about as informative. Suppose that Hastings intends to create an action-painting by dropping a bucket of paint onto a canvas. Unfortunately, he is so distracted in his admiration of a passing sports car that he involuntarily loosens his grip and drops the bucket onto the canvas. The result looks like an artwork-in fact, it looks much as Hastings hoped it would!- - but is actually non-art because the chain of events leading to its creation does not correspond to Hastings's intentions. According to the standard taxonomy, this is a complex failure; on my view, it is a straightforward performative failure. ${ }^{14}$ The causal chain corresponds to Hastings's practical reasoning, but the end product nevertheless seems unintentional.

To explain this discrepancy we could introduce a restriction to the effect that the intended goal must obtain "in the manner intended." "The manner intended" should therefore be understood in terms of producing a result in a particular way, under the guiding hand of a direct intention. With respect to the case above, we might then say that although Hastings intended to produce a particular arrangement of pigment by deliberately pouring the bucket onto the canvas, that is precisely what he failed to do-so the result is complex failed-art. Although this is a plausible line of response, the identification of "the manner intended" with direct intentions risks setting conditions on art-making that are so strict as to be descriptively inadequate. Allow me to explain.

\footnotetext{
14 That said, there is nothing to prevent Hastings from appropriating the product of that failed first attempt and presenting it as, e.g., found art—note only that doing so requires the formulation of a new art-attempt.
} 


\section{V - The manner intended}

Thus far, my talk of the intentions underpinning attempts in general, and art-attempts in particular, has been overly simplistic. I have been assuming (for the sake of clarity) that we were only dealing with one or two specific, goal-directed intentions. But, as Michael E. Bratman has observed, much of our ordinary planning is not like this: the intentions we formulate are typically just elements in larger plans. ${ }^{15}$ While some of our plans specify the exact means of their execution, we much more commonly settle on partial plans whose details we expect to fill in as time goes on. This is especially true for complex plans, which are hierarchically structured: a plan concerning an overall goal will embed sub-plans with preliminary goals and the means of achieving them, etc. ${ }^{16}$

As Bratman puts it, we formulate our plans "at a level of abstraction appropriate to [our] habits and skills." ${ }^{17}$ So, for instance, when I plan to teach a class, I do not ordinarily also formulate a sub-plan to take this bus at that time; instead, I do what I always do, which is get to a stop and wait for the next bus going to campus, whichever one it may be and at whatever time it comes. My plan does not require me to explicitly fill in these details, because I am simply relying on my habitual behaviour. I fill in the details-including specifications of means - as time goes by. And doing so is perfectly rational and useful, since the world changes in ways we do not always anticipate, making meticulously-detailed plans a waste of time and energy. From the ferry, for example, I can take the 257 to connect to either the 239 or the 255 buses to campus. I could slavishly commit to one or the other ahead of time, but why bother? Much better to wait and see which comes first.

\footnotetext{
15 Bratman (1999: 24).

${ }^{16}$ See Bratman (1999: 25).

17 Bratman (1999: 26).
} 
Similarly, artistic practices are much messier than toy examples allow and often involve processes of trial and error, revision and editing, and a fair amount of luck. According to Bratman's planning theory of intention, "plans are not merely executed. They are formed, retained, combined, constrained by other plans, filled in, modified, reconsidered, and so on." ${ }^{18}$ Speaking of artistic practice, Michael Baxandall likewise observed that

\begin{abstract}
A static notion of intention, supposing just a preliminary stance to which the final product either more or less conforms, would deny a great deal of what makes pictures worth bothering about, whether for us or for their makers. It would deny the encounter with the medium and reduce the work to a sort of conceptual or ideal art imperfectly realized. ${ }^{19}$
\end{abstract}

Similarly, Denis Dutton has observed that "in the sense of using skill to produce a preconceived result, creative artists strictly speaking never know what they're doing." 20 The point here is not that artistic activity is random, but rather that the making of artworks - indeed, the execution of any complex plan-requires the agent to make any number of discrete decisions, revisions, cancellations of previous actions or intentions, decisions not to do certain things, and so on. It also typically involves many different (sometimes competing) levels of intention: to make an artwork, paint a portrait, paint a photorealistic portrait, paint a photorealistic portrait of $X$, to paint a portrait that will change the artworld, or infect its audience with melancholy, to use these brushes and those paints, and so on. As Baxandall observes, each of these moments has an impact on the final product; the artist's intentions undergo some amount of modification in the process of creating the work in question. The final work stands as a declaration, ex post facto, of the artist's intentions, but it also stands as one episode in "a serial performance of problem-stating and problem-solving."

\footnotetext{
18 Bratman (1999: 12).

${ }^{19}$ Baxandall (1985: 63).

${ }^{20}$ Dutton (2009: 227-8).

${ }^{21}$ Baxandall (1985: 66).
} 
The goals of artistic practice, then, often do not obtain in quite "the manner intended;" at least, not in the sense of detailed specifications. The manner, rather, is negotiable at every step in the process of making. Just think of poor Apelles, who flew into a rage of despair when he found that he couldn't paint the foam on his horses just so. In his fit of pique, he threw a sponge at his painting and thereby achieved the very effect he'd failed to reproduce using all of his skill. ${ }^{22}$ The point of the story, as it is related by several grey eminences, is that Apelles needed a fortuitous accident to finish his painting as he wanted it: without that element of luck, he could not have finished his project. As Dio Chrysostom puts it, "at the sight Apelles was delighted by what Fortune had accomplished in his moment of despair and finished his painting, not through his art, but through the aid of Fortune." ${ }^{23}$

It strains credulity to think that the culmination of Apelles's efforts is a work of complex failed-art simply due to the minor element of chance involved in its creationespecially if he pulled off the rest of his painting without a hitch. When chance affects an element central to a work's identity, we might reasonably expect to call such a work failed-art because the strength of coincidence is such that without it, the action itself would be counted a performative failure. This is not the case with Apelles's painting. The standard taxonomy, however, would have us overstate the impact of luck in this case: Apelles did not achieve his foam "in the manner intended," and so his picture is a piece of complex failedart.

We could, of course, imagine a version of the legend according to which Apelles simply gave up after his fortuitous fling. Perhaps, according to this version, the whole point

\footnotetext{
${ }^{22}$ The legend is related by a number of ancient scholars, including Sextus Empiricus (1996: Bk. I, \$12, p. 7), Dio Chrysostom (2017: Discourse 63, p. 417-8), and Pliny the Elder (who ascribes the legend to Protogenes and Nealces; 1634: Natural History Bk. 35, Ch. 10, \$635, p. 1977-8). I am grateful to an anonymous referee for these additional sources.

${ }^{23}$ Dio Chrysostom (2017: Discourse 63, p. 417-8).
} 
of Apelles's project was to demonstrate that his skill and talent were up to the task of exact replication. In that case, his accidental success was not so happy, since it undermined the entire point of his endeavour. Indeed, this is just how Paisley Livingston suggests we read the story, and such a reading sees Apelles generating a piece of failed-art. ${ }^{24}$

There is no doubt that the finishing touch here was entirely accidental. The question is whether that fact travels up the hierarchy of intentions to render the outcome of Apelles's entire project accidental. And that will depend on just what his plan was. Generally speaking, a plan's lower-level elements represent preliminary steps towards achieving some of the plan's goals, so the failure of a lower-level element need not jeopardise the entire plan. ${ }^{25}$ So, for example, if Livingston is correct that Appelles's goal was to produce a photo-realistic picture without the intervention of luck, then the answer has to be 'yes': it is a failure, because Appelles's plan sets specific constraints on its lower-level elements, which the accident violates. If, on the other hand, his goal was more general, e.g. to paint a photo-realistic picture, then this small twist of fate does nothing to undermine his project as a whole, since it is perfectly consistent with the project's identity-conditions. Plans can change, of course, especially in response to the particular challenges one faces in the production of some object, or as one develops a more concrete idea of what it is one wants to do. We must be careful, however, to heed the point of the legend, which is that accidental results are part and parcel of the process of artistic creation. The stricter the requirements of "the manner intended," the less capable it is of handling such accidents without counting the whole work as accidental; conversely, the looser its requirements, the less effective it is in excluding deviant performances.

\footnotetext{
24 Livingston (2005: vii-viii). James Harris draws a similar lesson in his Three Treatises (1765: 6-7, 17 ff.). Thanks are again due to an anonymous referee for this source.

25 Bratman (1999: 35).
} 
Part of the problem here stems from treating failure as a property of particular works rather than of particular attempts. There is something misleading in talking about failed-art, as though the entities in question exemplified the property of failure in the same way that an apple exemplifies redness or an orange roundness. Imagine we did the same for our talk of artworks, so that instead of 'art' we said 'successful-art' (i.e. the product of a successful artattempt). The construction looks like it predicates success of the artwork, just as 'failed-art' looks like it predicates failure of the artwork, treating it like a complex predicate. It thus runs the risk of being mistaken for an evaluative rather than an ontological claim. Appropriately flagged, this is a mostly harmless side effect: it is much easier, after all, to use 'failed-art' as a component part of a sentence than it would be to use 'product of a failed art-attempt.' Unfortunately, the locution lends itself to obscuring the fact that it is the attempts which do all the work here; the individual works just take the ontological credit. Success and failure are properties of attempts (or of the events that contain them), not of the products of those attempts (except analogically-speaking). The products owe their existence to the attempts which generate them, and these attempts have their success- and failure-conditions set, as we have seen, by the nature of the goal which holds them together. Properly speaking, the failure in 'failed-art' attaches to the art-attempt, not to the art.

When we think of failure in terms of failed-art rather than failed art-attempts, it is easy to forget that we are actually giving a very general characterization of real-world practices. Indeed, thus far my talk of art-attempts has been at the general level: I avoided endorsing any particular combination of necessary and sufficient conditions for art, while recognizing that the actual application of this schematic treatment of attempts to 'art' requires some such commitment to a theory of art. But nobody needs a theory of art to see that actual artistic practices are much more complex than the preceding characterization 
makes them out to be. This is why we cannot just rely on "the manner intended" to mark the boundary between success and failure.

The point of Baxandall's and Bratman's interventions is to show that our complex plans_-including our artistic practices_are governed by a hierarchy of intentions, some more general in scope (e.g. to make an artwork), and others less so (e.g. to paint a portrait of $X$ ). More general intentions are capable of supporting more changes than less general intentions, since their generality leaves them open to more ways of being satisfied. Changing a higher-level element in the plan (e.g. a change of overall goal) will entail changes to the lower-level elements falling under them—so, for example, if Amyas Crale decides to sculpt Haraldr Harðráði rather than paint him, he must also change his intentions with respect to how he was going to represent him. Changes of lower-level elements, however, need not entail higher-level changes: if Crale decides to paint an abstract rather than a photo-realistic portrait of Harðráði, then his intention to paint a portrait of Harðráði remains unchanged, as does his intention to generate a painting.

Baxandall's and Bratman's observations hint at a better explanation of what happens in Apelles's case: the finishing touch is an entirely accidental one but, once the effect was achieved, Apelles licensed it by incorporating it into his work and letting it stand ${ }^{26}$ In so doing, Apelles declared his intentions-but the declaration was made ex post facto, not ex ante. The question of whether some particular result conforms to one's intentions is not one that is necessarily settled beforehand, but rather one that is usually avowed after the fact. Planning is not a static activity that entirely precedes an agent's action; it is a dynamic process sensitive to the challenges of the occasion. Plans-especially artistic plans-develop as the agent pursues them, tests their limits, and overcomes the accidents and obstacles that crop up.

\footnotetext{
${ }^{26}$ At least, he does so according to Dio Chrysostom's telling.
} 
What matters is not whether the final product is exactly as envisaged by the agent at the outset, but rather that its final form satisfies the requirements set out by her higher-level planning through a chain of intentional actions. Some may find this requirement surprisingly weak, but it is the best we can do in a world replete with indirect attempts and incidental artmaking.

\section{VI - The attempt-theory of failure}

Where does all this leave failed-art theory? I think we can identify three desiderata from the foregoing arguments: (1) first, an analysis of failure should be concerned with attempts, not objects and their properties; (2) second, this attempt-theory of failure must be sensitive to the conformative and performative senses of failure, and all that these entail; and (3) third, our account of failure should not rely on an unanalysed notion like 'the manner intended' to secure its verdicts-ideally, it should help to cast some light on just what we mean by 'the manner intended'.

These desiderata suggest a nimbler account of failure-and of failed-art in particular—modelled on Mag Uidhir's original:

Attempt-Theory of Failure

(1) Attempt Condition: An agent $A$ initiates a direct or indirect $F$ attempt.

(2) Failure Condition: $A$ 's F-attempt fails.

a) The $F$-attempt fails conformatively or

b) The F-attempt fails performatively

(3) Failed-F Condition: Because of the way in which $A$ 's F-attempt failed in (2), the product $p$ of $A$ 's actions is non-F.

The disjunction in the Attempt Condition makes explicit the fact that not all attempts are the same; and we need to explicitly reference an attempt's orientation because that is what determines the ways in which it can fail in (2). The Failure Condition simply requires that the attempt in (1) fail-and, as we have seen, there are two distinct senses of failure, the 
conformative and the performative. The requirement is not (yet) that the product of the $F$ attempt be non-F (since that would skirt too close to begging the question) but simply that the F-attempt fails. And as we know from the foregoing discussion, if A's F-attempt was direct then that failure can be either conformative or performative; if indirect, then it must be performative. So the orientation of the attempt in (1) determines the ways in which that attempt can fail in (2). Finally, the Failed-F Condition explains that the product of the Fattempt must be non- $F$ as a result of the failure identified in (2). Our Failed-F Condition is thus able to perform informative work: it tells us that in order to get failed-art, for example, the agent's art-attempt must end in conformative failure. And that, in turn, can only happen if the attempt in question was a direct art-attempt.

Armed with this machinery, we can finally explain Apelles's horses and give an exhaustive account of the different types of failed-art while preserving our commitment to the dynamism of artistic practice. Some failed-artworks are failures because something went wrong with the execution of the art-attempt (performative failures), and some because of a mismatch between the actual and intended final products (conformative failures). So far as Apelles is concerned, we can discern at least three separate levels of intention in his story, all operating over different spans of time. At the highest level of description, Apelles's horses are the result of a directly intentional process (a process with an explicit intention to paint a picture containing horses as a component part) that takes place over the duration of his painting activity. Call this his picture-attempt (P-attempt). Because Apelles's $P$-attempt is direct, his efforts can fail either conformatively or performatively (still speaking at the most general level). At this level, however, we have no failure, at least according to the way the legend is usually told: Apelles ultimately successfully painted his picture and it looked as he'd anticipated. 
Under the umbrella of his art-attempt, however, we can also discern a secondary direct intention to paint Poseidon's horses in a particular way; call this his $H$-attempt Apelles's $H$-attempt only covers a portion of the time covered by his $P$-attempt (viz., the span over which he is concerned with painting his foamy horses). Apelles uses all his skill to render the horses (his $H$-attempt is performatively successful), but the end result is not quite as he wants it: the $H$-attempt is, at least initially, a conformative failure. I shall return to this attempt in a moment.

Finally, in the course of painting his picture Apelles undertakes a tertiary attempt when he flings his sponge at the offending picture; call this his F-attempt. Flinging the sponge is directly intentional, and is in fact successful: Apelles throws his sponge at the painting and hits it, as intended. The success conditions for Apelles's F-attempt (that the sponge hit the picture, or perhaps the horse-part of the picture) do not entail the satisfaction of the conditions for his $H$-attempt, so Apelles's F-attempt does not incidentally satisfy his $H$-attempt. The fact that the F-attempt resulted in satisfying the goal of his $H$-attempt is entirely accidental.

Why doesn't the conformative failure attached to Apelles's $H$-attempt travel up the line to infect his $P$-attempt? Quite simply, because the $P$-attempt does not end there! Apelles has not given up his $P$-attempt, he merely has a fit of rage that involves undertaking a new attempt. It remains open to Apelles to give up, to erase the accident and try again (perhaps with some new techniques), or simply to accept the result of the accident and let it stand as a retroactive declaration of his intentions, à la Baxandall.

To the extent that Apelles painted foamy horses by flinging his sponge at his painting, his success is accidental because Apelles does not attempt to paint his foamy horses by throwing his sponge at the work (the $F$-attempt is neither a direct nor an indirect $H$ - or $P$ - 
attempt). If his F-attempt had failed (e.g. because the sponge missed its target), Apelles would be left with his initial failed $H$-attempt plus a failed $F$-attempt, but no more or less: by itself, the failure of the F-attempt would have no additional effect upon the product of his earlier attempts - unless, perhaps, it caused him to abandon his P-attempt entirely (thus resulting in a performative failure).

Ultimately, the effect achieved follows from Apelles's plan because he changes his plan to accommodate it. Nor is this a unique result — the same will be true of any complex, partial plan. Apelles had to change his plans a number of times in the course of executing his $H$-attempt, since he was never quite successful in achieving the intended effect. The standard taxonomy of failure would have us class the product of Apelles's artistic activity as a piece of complex failed-art (or, at least, a complex failed $H$-attempt). It should be clear by now, however, that this is the wrong result, because it asks us to evaluate the success or failure of an activity before its proper termination. It does not do justice to the many different attempts over time that we actually group together as Apelles's P-attempt.

\section{VII - Conclusion}

I have argued that thinking of failure in terms of objects (or: failed-objects) and their properties neglects the influence of an attempt's orientation, which determines that attempt's failure profile. The result is a flawed framework of failure and, by extension, an inadequate account of failed-art in particular. I argued that the standard framework is flawed in three important respects: (1) because it is extensionally inadequate, offering us a blunt account of the nature of attempts and their failures where what is needed is a more fine-grained approach, (2) because it overinvests in the constraining influence of the platitudinous 'manner intended', with the result that it proves descriptively inadequate where any but the 
simplest plans are concerned, and (3) because its application to particular cases, such as that of art-making, is insufficiently informative. I suggested, instead, that taxonomies of failure should focus on the attempts which generate failed-entities, and should therefore be sensitive to the different orientations an attempt can have, and to the different ways in which our attempts can fail. The result, I hope, is an improved taxonomy which can deliver real insights about particular intention-dependent practices. Where art and art-making are concerned, for instance, we are left with three important new insights into artistic practice: (1) pace Lopes (2007), there can be no 'accidental' art, only deliberate or 'incidental' art; (2) while performative failure is a necessary corollary of art-making, pace Mag Uidhir (2010, 2013) the possibility of failed-art is not; and (3) art's intention-dependence is entirely compatible with the role that luck plays in artistic creation, because the hierarchical nature of the planning involved in art-making means that the accidental fulfilment of a lower-level element need not undermine a higher-level plan's direct or indirect intention-dependence. ${ }^{27}$

\footnotetext{
27 I owe many thanks to Zach Blaesi, Emily Carson, David Davies, and Sherri Irvin for their insightful comments on previous drafts. This research was supported in part by grants from the Fonds de Recherche du Québec-Société et Culture and the Social Sciences and Humanities Research Council of Canada.
} 


\section{Works Cited}

Baxandall, Michael. Patterns of Intention: on the historical explanation of pictures. New Haven: Yale University Press, 1985.

Bratman, Michael E. Intention, Plans, and Practical Reason. Cambridge, Mass.: CSLI Publications, 1999.

Davies, David. "Mag Uidhir on what is 'minimally viable' in 'art-theoretic space'." Journal of Aesthetic Education 52, no. 2 (2018): 8-22.

Dio Chrysostom. The Complete Works of Dio Chrysostom. Translated by J. W. Cohoon. Hastings: Delphi Classics, 2017.

Dutton, Denis. The Art Instinct: Beauty, Pleasure, \& Human Evolution. New York: Bloomsbury Press, 2009.

Harris, James. Three Treatises. Second Edition. London: I. Novrse \& P. Vaillant, 1765.

Hart, H.L.A. Punishment and Responsibility. Oxford: Oxford University Press, 1968.

Livingston, Paisley. Art and Intention: A Philosophical Study. Oxford: Oxford University Press, 2005.

Lopes, Dominic McIver. "Art Without 'Art'." British Journal of Aesthetics 47.1 (2007): 1-15.

Mag Uidhir, Christy. Art \& Art-Attempts. New York: Oxford University Press, 2013.

—. "Failed-Art and Failed Art-Theory." Australasian Journal of Philosophy 88.3 (2010): 381-400.

Nagel, Thomas. Mortal Questions. New York: Cambridge University Press, 1979.

Paul, Sarah K. "Embarking on a Crime." Law and the Philosophy of Action. Ed. Enrique Villanueva. Rodopi, 2014. 101-24.

Pliny the Elder. The Historie of the World: Commonly Called, The Naturall Historie of C. Plinius Secundus. Translated by Philemon Holland. London: Adam Islip, 1634.

Sextus Empiricus. Outlines of Pyrronism. Trans. Benson Yates. New York: Oxford University Press, 1996.

Williams, Bernard. Moral Luck. Cambridge: Cambridge University Press, 1981.

Yaffe, Gideon. Attempts: In the Philosophy of Action and the Criminal Law. New York: Oxford University Press, 2010. 